\title{
DEVENIR MUJER MENSTRUAL ESCRITURAS ENTRE GÉNERO, CUERPXS Y PERFORMANCE EN LA OBRA DE EFFY BETH
}

Ornela Barone Zallocco ${ }^{\mathrm{i}}$

Santiago Díaz ${ }^{\text {ii }}$

\begin{abstract}
Resumen: En el presente artículo se ha buscado acompañar la obra performática corporante de la artista trans Effy Beth, devenida en mujer y las travesías que marcan huella en dicho carnaval. El ciclo menstrual de Effy es la realidad ficcionalizada que logra corromper los estatus de la moral, de la verdad, de lo normalizado y heteronormado. Se (re)crea en una vida (im)posible mediante sus obras, escrituras y conjuros. Con una fuerza impactante la artista despliega, abriendo paso al pensamiento, la matriz más fértil que puede reproducir ideas, escrituras y obras que logran hacer que este mundo tiemble.
\end{abstract}

Palabras clave: Menstruación; Performance; Género; Corporalidades.

\section{BECOME A MENSTRUAL WOMAN SCRIPTURES BETWEEN GENDER, BODIES AND PERFORMANCE IN THE WORK OF EFFY BETH}

\begin{abstract}
In this article we have sought to accompany the corporative performance work of the trans artist Effy Beth, turned into a woman and the journeys that mark this carnival. Effy's menstrual cycle is fictionalized reality that manages to corrupt the status of morality, of truth, of what is normalized and heteronormed. He (re)creates himself in an (im)possible life through his works, writings and spells. With an impressive force, the artist unfolds, making way for thought, the most fertile matrix that can reproduce ideas, writings and works that make this world tremble.
\end{abstract}

Keywords: Menstruation, Performance art; Gender; Corporalities.

"Una vez una persona me dijo:

aunque vos te sientas mujer, te crezcan las tetas, tomes hormonas, te operes los genitales, nunca serás mujer porque no menstruás ni sabés lo que eso significa”. Effy Mia Chorubczyk

Este artículo, escrito en conjunto entre un "hombre" incómodo con las implicancias de tal etiqueta y una "mujer" incómoda con los estereotipos y narrativas arraigadas a tal condición. Se encuentran, entrelazan y figuran en un registro de obra y cuerpx que pretende ser sensible, erótico y respetuoso, a la vez que se saben por fuera de un cuerpx transgénero. Por tanto, todo (c) (1) (2) Creative Commons Atribuição Não Comercial-Compartilha Igual (CC BY-NC-4.0), que permite uso, distribuição e reprodução para fins não comerciais, com a citação dos autores e da fonte original e sob a mesma licença. 


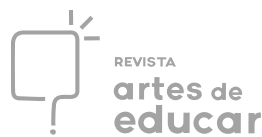

lo aquí expuesto y narrado tiene por objeto compartir el recorrido estético-político de esta artista, la permanencia y vitalidad propias de su ser, de sus performances, de su existencia. En el anhelo de que, las huellas de su transformación, performatividad y vitalidad logren permear la opacidad del tiempo y sean encontradas en las memorias de cada ser que las sepa atesorar y necesitar para la existencia propia.

Nunca serás mujer es una literatura íntima y performática escrita desde y con el cuerpo. Distópica y cíclica, se desarrolla situando en el cuerpo los márgenes, las heridas del sexo y del género. Establece discusiones atemporales en un plano subjetivo, íntimo y político. Vuelve materia vital los contenidos teóricos, estéticos y epistémicos. Incomoda y hace cuerpo marcando el propio, porque lo colectiviza, porque devela la tensión subyacente de lo político.

Por Josefina Alcázar (2014: 85) sabemos que el cuerpo, en una acción performática, ya no representa ni hace "como sí", sino que es una vibrante transformación. En esta performática autobiografía, la autora se siente en la libertad de exponer la importancia de su vida, de su mundo íntimo, de su transformación deseante. Se siente habilitada a ser autora de sí y exhibir las confesiones de la gestión de su identidad de género. "Utilizando la propia constitución del Yo, mientras se lo va generando" (Amícola 2007: 2). En efecto, “Autobiografía y género, ambos reproducen la metáfora del velo que, aun cubriendo y enmascarando el vacío, constantemente lo grita y lo convoca” (Calafell Sala 2007: 93). Los vacíos son convocados por la autora no como propios, sino extendiendo tal sentido a todos los vacíos de lo visto, experimentado y catalogado en relación a la intersección entre la subjetividad, el cuerpo transgénero y el ciclo menstrual.

En estos relieves y texturas, superficies de lo que transmuta, se inscriben las narrativas que abren paso a consideraciones de la subjetividad no limitadas al sujeto, sino vinculadas a su red de relaciones, a las tramas profundas que se abren en tejidos inimaginados. En este sentido, escribir lo propio es un relato que coescribe los relatos, experiencias y circunstancias contextuales, donde todo se da en un entrecruzamiento texturado, vivencial e indiscernible.

En ese allí y entonces que nos invita Muñoz (2020: 16), dónde se desarrolló la performance de Effy, en esa sociedad normalizada y normativa, que aún perdura sin muchas modificaciones, esta artista se abrió paso para hacer(se) cuerpx en una lucha colectiva, y encarnar una utopía de muchxs por desidentificarse (Muñoz 2020: 27) de los patrones sexogenéricos y establecer con la herida que esta operatoria conlleva, el signo de su propia constitución. Las acciones que trazan su performance siembran las dudas e incomodidades de la normalización, juega con el sexo y con el género, con las categorías instituidas y los estereotipos instituyentes. Desarma las narrativas colonizadoras, desestabilizando lo aprendido Revista Interinstitucional Artes de Educar. Rio de Janeiro, V. 7, N. 1 - pág. 171-189 janeiroabril de 2021: "Pedagogias Vitais: Corpo, Desejo e Educação" DOI: 10.12957/riae.2021.51642 


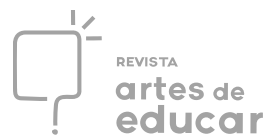

y reconocido, escribiendo desde y en el cuerpo propio, volviéndose materia viva de su propia autobiografía de transfiguración.

La identidad genérica femenina condenada al clóset cuando se devela menstrual, es la misma que se le exige sexogenéricamente a quién se autopercibe como mujer, pero no menstrua. "No es el cuerpo, sino la mirada sociodiscursiva posada sobre él lo que causa su reacción” (Calafell Sala 2007: 96). El signo de "ser mujer" (entre otros) está otorgado por la presencia de la sangre menstrual, aunque la misma deba privatizarse y condenarse al oculto ámbito de lo privado, a la moral de la habitación y el secreto familiar. Devenir mujer, en la interseccionalidad de ser artista judía transgénero nacionalizada argentina, lleva a Effy, a cartografiar en trece menstruaciones sus deseos, sus procesos, sus afectos y sus heridas: una plataforma deseante de circulación activa y vital, su performance entrelaza las potencias de mutación que hacen de una vida la resistencia sensible ante las diversas modalidades de dominación que la colonialidad normalizadora despliega en todas las corporalidades. Por eso, las escrituras sensibles desde y en el cuerpo de Effy, se "despliegan sobre una materialidad corporal que impugna la mirada propia y ajena, perfora la línea que separa el exterior del interior, y se constituye en la parte otra de un eterno diálogo entre el yo y el otro (...)" (Calafell Sala 2007: 97)

\section{"Yo era mujer antes de esto, ¿por qué entonces exteriorizar mi identidad?"}

Los múltiples artificios creados como incesante búsqueda para pertenecer a las formas ordenadoras del género, se gestan en las percepciones, los discursos, las enunciaciones, las formas de ver y nombrar de quienes, desde afuera, constituyen despóticamente la subjetividad. Effy se sabía mujer, y aun así sintió la imperiosa necesidad de reafirmar su identidad, de exteriorizar para la mirada del afuera. Lo que las miradas piden ver y lo que es visto, lo que es percibido y enunciado, construye y entrelaza nuestros relatos con los mundos. El campo escópico hegemónico establece modalidades de una exigencia estricta, que el afuera impone desde ciertas categorías sexogenéricas predeterminadas, provocando patrones de normalización, regulación y evaluación de las formas de vida. Todos esos discursos y narrativas invaden el espacio de lo propio, del adentro, del "yo". Del "yo" y de todos los "yo" que no son individualidad sino colectivo de subjetividades sometidas, heridas e invisibilizadas al espacio de lo abyecto, de lo oculto e indecible. Retomando lo propuesto por Calafell Sala, el cuerpo es un texto edificado sobre una base liminar y ambivalente donde se ven atravesadas las marcas 
del sexo y del género, dibujando los restos de su exclusión de un afuera que es constitutivo del adentro del sujeto (2007: 91).

Siguiendo lo propuesto por Wittig "el lenguaje proyecta haces de realidad sobre el cuerpo social, lo marca y le da forma violentamente" (2018: 111). En este sentido, la apropiación de los discursos del afuera en la recomposición de la corporalidad hacia el adentro, manifiesta la necesidad de relatar de manera autobiográfica lo indecible, de hacer carne y vida aquellas palabras que nombran un sentir rebelde, resistencia nacida de un deseo ingobernable. En efecto, la feminidad, como ficción realista, vela algo irreal, algo construido y constituyente, vela la nada, sostiene lo que no existe como afirma Mattalia retomada en Calafell Sala (2007: 93). Reproduce un concepto de "ser mujer" organizado y sustentado en las bases de un sistema capitalista colonial, que explota y somete las sensibilidades, dando de "molaridad" configurante a base de una sistemática organización histórica que ordena la vida propia, ajustándose a los modos identitarios de la lógica binaria heteronormativa. En la aporía de ficciones violentas, silenciosas y microfísicas, que se inscriben en lxs cuerpxs sujetados a lógicas de feminidad, se fractura lo más profundo y afirmativo de la vida: el deseo. Como sabemos desde la propuesta de Spinoza, retomada por Deleuze y Guattari, el deseo no está estrictamente vinculado con la sexualidad, ni con la carencia, ni con la falta, sino que es mucho más potente en su esencia: el deseo es plena potencia de afirmación de todas las posibilidades que nos habitan (Deleuze \& Guattari 2010: 45). El deseo es una fuerza activa de producción de signos abiertos que traman una constelación de sentidos, no figuran una identidad "molar", sino un modo de existencia que se define y regula según la propia lógica deseante, se sostiene en las líneas vitales que extiende la composición actual de una afirmación que el deseo expresa.

No es una expresión voluntaria, ni siquiera consciente, esa afirmación deseante arrebata toda contención impuesta por el afuera, lo desestabiliza, lo confronta, por eso mismo, el deseo es un foco de atención de todos los dispositivos de la colonialidad patriarcal, porque pone en "riesgo" el ordenamiento binario de la sociedad, de la humanidad, del mundo. El desafío más inquietante que plantea un modo de existencia deseante es que no puede ser predecible, ni regulado, ni ordenado de manera externa ni tampoco prever sus expresiones. Effy hace estallar los grilletes de la moral hegemónica que impone una sangre secreta al cuerpo femenino, y abre su cuerpo a las intensidades de un devenir-mujer, un devenir-minoritario, un devenir-sangremenstrual, porque la sangre menstrual es un devenir revolucionarix en el cuerpo trans, que interviene la misma hegemonía de la visibilidad de la propia sangre, sabiendo que solo la sangre de la violencia, la masculina, de la guerra, del combate, es la única sangre posible de ser vista y aceptada. La sangre de Effy es la transmutación de todos los valores morales, políticos y Revista Interinstitucional Artes de Educar. Rio de Janeiro, V. 7, N. 1 - pág. 171-189 janeiroabril de 2021: "Pedagogias Vitais: Corpo, Desejo e Educação" DOI: 10.12957/riae.2021.51642 
ciudadanos, es el grito-sangre de una libertad que siempre es incomprensible para quienes se encargan de administrar despóticamente los derechos y las libertades. Es una libertad inaccesible, inimaginable, inalcanzable, para los policías de la moral heterosexual.

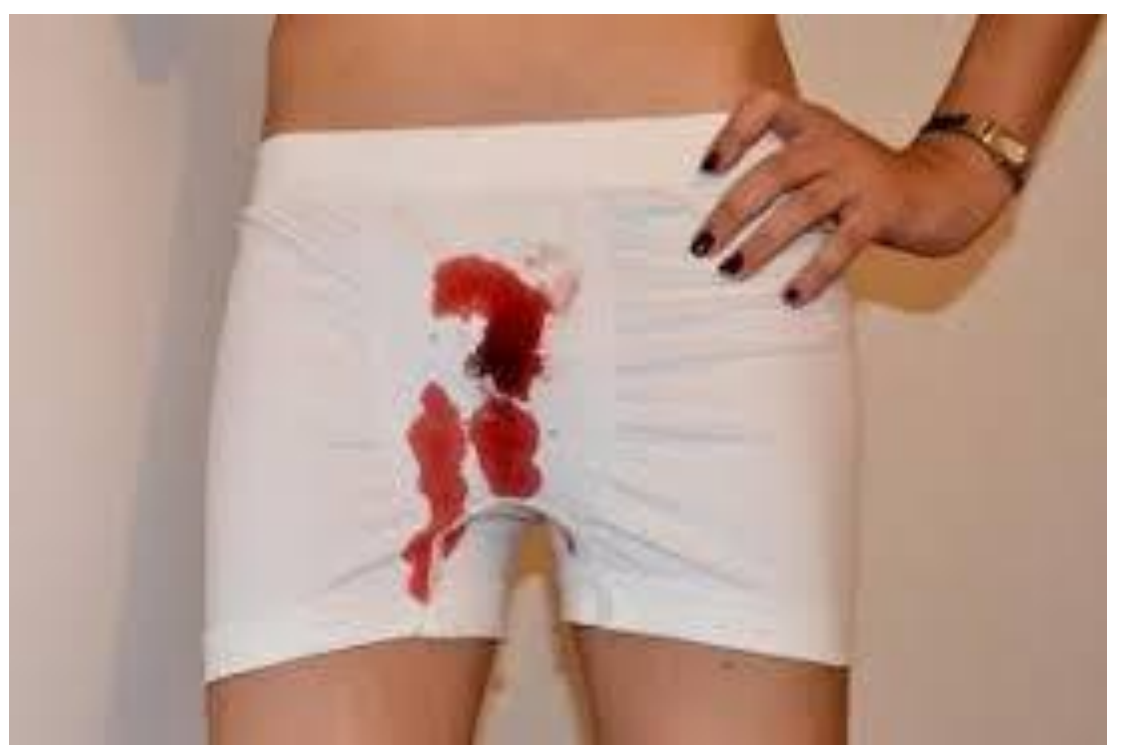

Figura 1: Effy: "me pongo ropa interior masculina y disuelvo en ella lo extraído en representación de mi primera menstruación".

\section{“Mi nombre es Elizabeth Mía Chorubczyk, Presente."}

¿Podemos pensar el trabajo autobiográfico de Effy como una ficción? Si "la autobiografía gira en torno a la posibilidad e imposibilidad del lenguaje para ser expresión de la realidad, concretamente de la realidad individual" (Laguna González 2005: 6) entonces ¿cuál es la realidad? ¿Effy crea una ficción de sí misma? En este último sentido, diremos, que si consideramos que todas las construcciones del sexo y el género son ficciones, entonces, sentirse mujer y presentarse como tal, habitando un cuerpx otro de "hombre", requiere de una ficción a ser desarrollada. De un relato a ser construido y narrado, en la necesidad de "buscarse, de reafirmarse, de ser verdaderas y que internamente atravesamos conflictos respecto a si la verdad se encuentra mediante el artificio, ¿cuál es el artificio? ¿Artificio es lo que tomamos o lo que somos? ¿Cuál es la mentira? (Faigenbaum \& Chorubczyk 2016: 84).

La construcción de la "mentira" en esta autobiografía íntima, sincera y descarnada, es a lo que la artista nos convoca una y otra vez. Nos vuelve partícipes de su proceso de transmutación, de transformación y ficción del "ser mujer" que impone el determinismo cultural. Lo que esta operatoria performática expresa no sólo es el proceso de autosubjetivación 


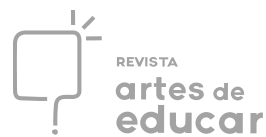

que realiza Effy, sino que pone de manifiesto que existe una sistemática silenciosa de captura y producción ficcional en todas las corporalidades. Considerando que la ficcionalidad de fondo es un modo de producir los modos de existencia. Podríamos decir que con Butler, somos una práctica performática que ficcionaliza la existencia, pero una ficcionalización que no tiene original. Así, como el femenino excede su figuración, el receptáculo o mater, plantea una imposibilidad de ser tematizado, a la vez que constituye lo femenino como fundamento imposible pero necesario de lo que puede ser tematizado y representado (Irigaray citada en Butler 2018: 76).

Desidentificarse de un esquema infiere como necesidad vital, encontrarse e identificarse con otro. Así lo hizo Effy cuándo decidió comenzar su tratamiento de reasignación hormonal. "debo experimentar cosas que no quiero porque de eso se trata la definición del sexo" narra Effy en su primera menstruación. Así, "traicionar" lo que la sociedad definió y escribió en la materia de tu corporalidad implica corromper los mandatos violentamente tatuados en la piel del sexo construyendo el género como consecuente y orgánico devenir. Esta contra-sexualidad gestada por Effy, como cuerpo político de expresión, desafiaba la materia del género y el sexo impuesto, no sólo en el propio cuerpx, sino en la obra que producía con el mismo. Hizo de su propio cuerpx un campo de batalla, de su intimidad -personal- una estética deseante que expandía una utopía existencial colectiva. Su cuerpx, una constelación afectiva de mil resonancias amigas, la insurgencia por venir.

Esta ardua y osada tarea de búsqueda, en caminos sinuosos y mortales del sistema capitalista colonial orientó a la artista a preguntarse, una y otra vez, por la necesidad de este tratamiento. "Aceptar que la identidad construida sobre un cuerpo es un mortífero juego de suplantaciones" (Calafell Sala 2007: 96) sugiere adecuar la materia del cuerpo a las normativas impuestas, para encajar en marcos definidos del género. Sin embargo, en consonancia con lo propuesto por Butler sostenemos “¿deben los cuerpos y las psiques abrirse simplemente a la inspección y a la invasión? (...) ¿Este es el precio que se debe pagar por llevar a cabo la transición deseada?" (Butler 2010: 10). En efecto, parece ser que para ocupar el espacio público del afuera, se requiere como condición sine qua non incorporar los textos y discursos socioculturales hacia adentro. Esa "incorporación" es la que se vuelve invisible como ficcionalidad política, la que programa la axiomática sexual que ordena la sensibilidad, las afecciones y los deseos, por eso la corporalidad que Effy compone trastoca la tecnología maquínica del género y disloca las zonas erógenas predeterminadas para la recepción común de los cuerpos femeninos. P. B. Preciado expresa que "el sexo es una tecnología de dominación heterosocial que reduce el cuerpo a zonas erógenas en función de una distribución asimétrica Revista Interinstitucional Artes de Educar. Rio de Janeiro, V. 7, N. 1 - pág. 171-189 janeiroabril de 2021: "Pedagogias Vitais: Corpo, Desejo e Educação" DOI: 10.12957/ riae.2021.51642 
del poder entre los géneros" (2000: 22). Lo que hace Effy es volver su cuerpo una territorialidad insurgente de contrapoderes y resistencias somáticas ante el imperativo heterosocial que menciona Preciado, lo destituye componiendo otra sensibilidad bajo la sensibilidad femenina, otra recepción y percepción de la sangre, inventa otra tecnología corporal, para un deseo dislocado.

Retomando la textualidad de su narración, la experiencia estética a la que invita la obra completa, implica relaciones binómicas entre la realidad y la ficción, el "mundo de la autora" y el "mundo" de quienes leen, ser hombre (en sus palabras "aún vistiéndome de hombre") o ser mujer, como ella se sentía. Una tensión que refuerza las polaridades y las estalla. Toda visión, toda percepción, es intencionalidad, dice la fenomenología, pero también, sabemos, es una tensión que abre la posibilidad de verse y percibirse. La apuesta performática de Effy desafía en ese intersticio, en ese "entre" que expresa las intensidades no muy bien definidas, pero siempre presentes y percibidas. En efecto, una de las capacidades que tenemos como seres humanos es la de mirarnos desde fuera y pensarnos. Muchas de nuestras preocupaciones y ficciones se orientan a reconocernos como algo, con una entidad definida, como persona, como ser. En este sentido, “...no sólo es fundamental que nos reconozcamos 'individualmente' como ser sino también han de hacerlo las demás en un proceso de influencia mutua. Porque ¿cómo puedo sentirme algo si las demás no me consideran como tal?” (Biglia \& Lloret 2010: 212). De esta manera, el "poder ser", si bien debiera configurarse como un derecho humano fundamental, se da por sobreentendido dentro de la hegemonía normalizadora, y por tanto bloquea, o dificulta, mediante la omisión o la violencia, las diversidades de otros "poder ser" diferentes. En estos relieves, surge la necesidad de hablar en primera persona junto a la autobiografía como género literario, para abrir paso a las confesiones del mundo propio de la autora, en este caso, y con ello, abrir la voz propia a la voz colectiva, el sentir personal que se vuelve manada y multitud.

Valiéndose de las tecnologías del yo (Cf. Foucault 2008), Effy, realiza gradualmente las modificaciones que considera necesarias "con el fin de autotransformarse para alcanzar cierto grado de felicidad, pureza, sabiduría, perfección o inmortalidad”. (Loureiro, 1993: 43-44 citado en Laguna González, 2005: 15). Lo que pone en relieve la misma condición esencial de toda subjetividad, el trasfondo procesual y autofigurante que subyace y no siempre es visible. Lo que Effy habilita es la potencia de las prácticas de libertad que yacen en el deseo de ser, de existir, y que, sabemos, los poderes despóticos de las identidades hegemónicas se encargan de hacer olvidar. 


\section{¿Cómo construye discursivamente el género?}

En esta obra autobiográfica el género de la autora se va construyendo a la vez que se fusionan sus espacios íntimos y públicos, y de manera simultánea, abriendo una tercera zona de lo indiscernible ontológicamente, se hibridan realidad y ficción. Su cuerpx, materia de la obra toda, sostiene la escritura a la vez que transmuta de signo. Las heridas, calan en lo más profundo de la sensibilidad corporal, en la piel, y en la construcción del género, desarmando cualquier estabilidad pretendida, desbaratando las certezas propias del espacio cotidiano.

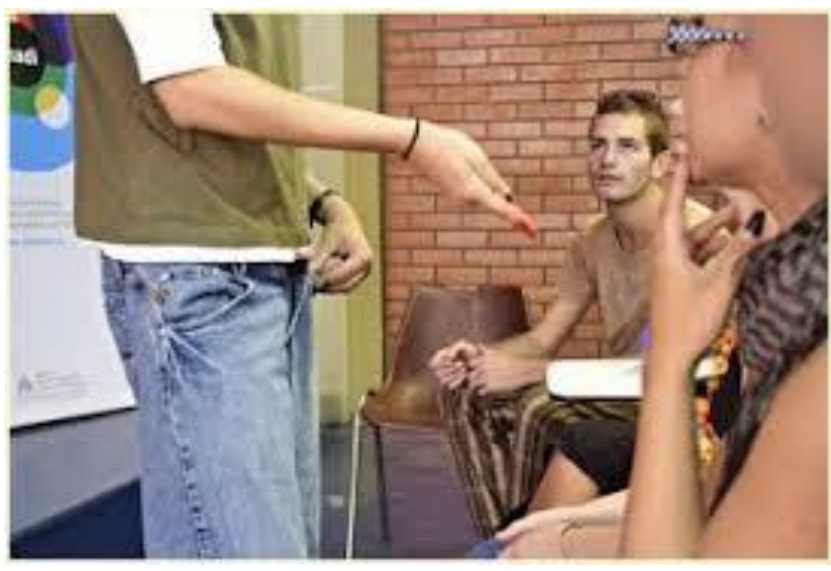

Escribir su "verdadero nombre" con sangre menstrual, ficcionaliza su historia y la recupera en forma de signos irreverentes, con toda la potencia viva del deseo emergente, capaces de hacer inmolar los mismos constructos sociodiscursivos, que violentan desde las axiomáticas "molares", esas que buscan regular, administrar $\mathrm{y}$ clasificar el deseo y las formas de vida, bajo lineamientos de una jerarquía existencial heterocentrada.

A partir de la segunda menstruación, Effy, provoca inestabilidad y distorsión de la percepción sexogenérica, conmociona la sensibilidad continua de la normalidad binaria. Para esto, concurre a la Facultad vistiéndose "de hombre y con barba en el rostro, me presento en clase como Effy" (Faigenbaum \& Chorubczyk 2016: 85). Queremos destacar que el resaltado es nuestro, para marcar la importancia de presentarse y no ser re-presentada bajo categorías impuestas. Además, la ausencia de modelos a "imitar" e incluso de visualidades que recreen o reflejen su experiencia, da cuenta de la necesidad de crearlas, narrarlas, escribirlas en primera persona desde el cuerpo y en el cuerpo, encarnar la propia identidad deseada desde una especie de brújula erótica, trastocando la expresión de Suely Rolnik (2018: 112). De esta manera, la provocadora artista aporta un desordenamiento del género, exhibiendo "los territorios limitrofes de su ser público y privado” (Calafell Sala 2007: 93).

Como máscaras que prometen una ilusión, de lo que no es sino de lo que se da a ver y se oculta a la vez, en relaciones tautológicas de presencia aurática, Effy se disfraza, dicho en sus propios términos, de hombre, y refiere en más de una ocasión la problematización que la vestimenta como signo de identidad le genera. El disfraz es un umbral de visibilidad y de enunciabilidad, es esa zona posible de ser habitada con un mínimo factible de respiración Revista Interinstitucional Artes de Educar. Rio de Janeiro, V. 7, N. 1 - pág. 171-189 janeiroabril de 2021: "Pedagogias Vitais: Corpo, Desejo e Educação" DOI: 10.12957/riae.2021.51642 
liviana, sin demasiadas opresiones y asfixias. El disfraz es esa diagramática vital que hace fluir una vida otra en medio de tanta normalidad justiciera. De ahí que los artificios necesarios para la construcción discursiva del género se produzcan performativamente por medio del disfraz, lo que viene a intervenir en la corporalidad bajo una diversidad de formas, texturas y colores. Siguiendo a Didi Huberman “dar a ver es siempre inquietar el ver, en su acto, en su sujeto. Ver es siempre una operación de sujeto, por lo tanto una operación hendida, inquieta, agitada, abierta" (2017: 47). Dar a ver, tejer esa visibilidad trastocada, es un modo de hacer ver lo que no se ve, o lo que se ve despectivamente, como horror o burla, y transfigurar esa mirada, más sobre sí, por esta potencia de afirmación que la imagen de sí conlleva y valorizar el sentido de una vida que porta la plena y efectiva existencia en consonancia con el deseo, esto abre un enorme alivio, dice Effy que tiene "un gran alivio de poder ser yo misma y no tener que prostituirme para que se respete el nombre que adopté al comenzar la transición" (Faigenbaum \& Chorubczyk 2016: 99).

Las vejaciones iteradas, insistentes, de la sociedad, conspiran al deseo y potencia del devenir mujer, y, en este sentido, tal como formula Effy entran muchos preconceptos en juego, que pocas veces son problematizados: ¿qué nos hace hombres y mujeres? ¿Las hormonas o la vestimenta? ¿El cuerpo o la mente? ¿Nuestro actuar o nuestro pensar? ¿Podemos transgredir el género desde nuestra construcción? ¿Ser mujer es pintarse las uñas, no puedo ser una mujer con barba o un hombre con flujos vaginales? (Faigenbaum \& Chorubczyk 2016: 110). Si consideramos la dirección o rectitud habitual de lxs cuerpxs, la linealidad en la que heterosexualmente los mismos se inscriben, podemos comprender por qué cuándo unx cuerpx se "desvía" de la rectitud y toda línea de ordenamiento normalizado(r), es señaladx, marcadx y/o estigmatizadx. Cuando unx cuerpx sigue y se orienta por las líneas de deseo que su propia singularidad existente expresa, desorienta los contextos dogmáticos y fiscalizadores de los modos de vida deseantes. En este sentido "habitar un cuerpo que no se corresponde con la piel de la sociedad significa que el mundo adquiere una nueva forma y crea nuevas impresiones" (Ahmed 2019: 36). Hay una apertura de nuevas sensibilidades que habilitan una imaginación política de lo corporal, singular y colectivamente. Lxs cuerpxs que se imaginan siendo lo que sienten ser, según la brújula erótica que los compone, abren ese imaginario de los entrecruzamientos, de las mixturas y pluralidades, un hacer y un pensar que desafía y problematiza -a costo de una alta cuota de dolor- las relaciones naturalizadas con las que la lógica heteronormativa regula todas las composiciones posibles de los géneros aceptados y valorados por esa misma moral del deseo. 
"Lloro de dolor mientras pienso por qué tengo que pasar por esa tortura, ¿por qué las mujeres no podemos ser bellamente barbudas? ¿Por qué debemos someternos a tratamientos dolorosos o gastar nuestro dinero en cumplir con un mandato social sobre lo aceptado, la belleza, lo atractivo y lo femenino?" (Faigenbaum \& Chorubczyk 2016: 92). Tal como lo enuncia Effy, la normalización es dolorosa, y más cuando se persigue el deseo, cuando lo que no se disfraza es el sentir, la manera de pensar. La heteronorma controla el cuerpx, toda la sensibilidad, y el discurso social que le nombra, territorializándolo dentro del sistema capitalista-moderno-colonial, con una fuerte referencia a las capacidades propias de esxs cuerpxs, todo un régimen capacitista que determina las existencias desde sus aptas o no aptas funcionalidades. De esta manera, "la heterosexualidad obligatoria determina lo que los cuerpos pueden hacer. Los cuerpos toman la forma de normas que son repetidas en el tiempo y con fuerza” (Ahmed 2019: 130). En este sentido, el “deber ser mujer”, a través de la tachadura del cuerpo, es callar, omitir, borrar aquello que no puede ser develado- y de lo que se inscribe en él de particularmente femenino. Aquellos discursos públicos sobre lo que son o deben ser las mujeres. El signo visual "mujer" se apuntaló en representaciones abstractas (o idealizadas) que "funcionan como pantallas en las que pueden disfrutarse las fantasías masculinas de conocimiento, poder y posición en un juego sin fin que se apoya en la obviedad de la mujer y en el tranquilizador disimulo de sus inextricables enigmas detrás de la máscara de la belleza" (Pollock 2013: 222)

La segunda, derivada de aquí, muestra en qué grado el deslizamiento del "ser" al "deber ser" (Calafell Sala 2007: 95), implica toda una performance constelar de acciones y figuraciones: el untarse de sangre menstrual la cara, a la vez que se depila el cuerpx, inscribe no sólo el género al que deviene, sino las imposiciones culturales que el mismo detenta para portar dicha identidad. Siguiendo a J. Butler (2005: 19), sostenemos el poder reiterativo del discurso para producir los fenómenos que regula e impone, determinando sociocultural y políticamente las formas que debe adquirir la materialidad de lxs cuerpxs, para ocupar el espacio de lo público, en una sociedad en la que "se contrae el circuito de los incluidos y se expande el cinturón de la exclusión” (Reguillo Cruz 2014:60). La performatividad no sólo compone unx cuerpx para ser habitado, sino también un modo de transitar los espacios, la manera de andar y atravesar el flujo semiótico con la que se embiste toda espacialidad: " $L a$ sexualidad puede ser considerada una formación espacial no sólo en el sentido de que los cuerpos habitan espacios sexuales (Bell y Valentine 1995), sino también en el sentido de que los cuerpos son sexualizados según cómo habitan el espacio” (Ahmed 2019: 97). De esta manera, desafiando todos los límites y orientaciones espaciales impuestas, Effy intervino el Revista Interinstitucional Artes de Educar. Rio de Janeiro, V. 7, N. 1 - pág. 171-189 janeiroabril de 2021: "Pedagogias Vitais: Corpo, Desejo e Educação" DOI: 10.12957/ riae.2021.51642 


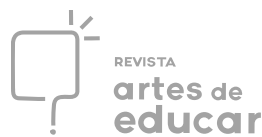

espacio de lo público con tampones "íntimos" saturados de sangre-grito expulsada de una cuerpa viviente y deseante, que "mancha" toda la blancura pulcra de las heteronormatividades. La mancha de la sangre menstrual en el liso e higiénico espacio público, pone en peligro esa empresa civilizatoria de la moralización y colonización de nuestros fluidos corporales.

Las narrativas que tejen la perfomance Nunca será mujer que Effy realiza, esas narrativas de la construcción del género, también aportan una sincronía en el ordenamiento temporal en que se escriben. La forma en la que se organizan los relatos que componen la autobiografía performática, si bien utilizan un tiempo cronológico y sucesivo, es, a la vez, cíclico, porque está basado en la ciclicidad del "ciclo menstrual", por lo tanto, la artista, desarrolla con su obra escrita y visual, trece menstruaciones que son las equivalentes a las trece lunas que acontecen en un año del calendario gregoriano.

En esta performance autobiográfica "elyo del escritor (en este caso, compositora) queda plasmado en la escritura (corporal) como un signo referencia de su propia existencia" (Laguna González 2005: 4). En este sentido, la escritura sensible de esta acción performática íntima, explora la fuerza semántica de una imagen de sí que porta una doble potencia de sentido: por tratarse, en principio, de un registro narrativo muy propio de la experiencia de transfiguración. Pero también está acompañada por la visualidad utilizada en su movimiento de afirmación y composición identitaria. En efecto, las imágenes fotográficas aportan una materialidad sensible expansiva que multiplica las dimensiones perceptivas y dan cuenta más profundamente de su experiencia, la ilustran pero no de forma decorativa, sino de una manera más bien texturada, como el ritmo mismo de su escritura, utilizando el lenguaje imago de los píxeles (en este caso) para establecer una expresión artístico-política que se narra en la mezcla, en la miscelánea de lo que se lee y percibe en términos textuales, visuales; de lo que se muestra y lo que da a ser visto, con lo que se oculta o se cercena a la vez que se exhibe en su textura emergente.

Las retóricas visuales utilizadas por Effy reclaman de las miradas la incomodidad. Orientan las comprensiones a la inestabilidad. Si consideramos que los objetos e imágenes junto a los que se piensa interactúan en la producción de significados, en el despliegue de los procesos de análisis y de comprensión del mundo en términos de co-presencia. "Las imágenes toman una vida, una fuerza performativa que participa de forma activa en las políticas del conocimiento, de la visión, y la visualidad, del tiempo y del espacio" (Martínez Luna 2019: 115). Effy, con suspicacia y sensible creatividad, gestó imágenes de lo inaudito, de los bordes de lo impensado, desconocido y abyecto. Quebró el pulso de la normalidad pretendida para abrir paso a la anti normalidad necesaria, deseada. 


\section{La escritura en lx cuerpx y junto a él.}

Retomando la pregunta acerca de ¿qué es “escribible”? podremos seguir preguntando interminablemente acerca de las consecuencias de escribir lxs cuerpxs y de inscribirnos en ellxs. Pensando en T. de Lauretis sostenemos que, "el viaje y la escritura ignoran el mapa, exceden las palabras del amo para exponer los intervalos, los vacios de representación, y penetran en los intersticios del discurso para re-imaginar, re-aprender, re-escribir el cuerpo en otra economía libidinal" (de Lauretis 2014: 26). De esta manera, el viaje que emprendió Effy cartografiando la escritura en su cuerpx le permitió producir un devenir mujer, abrir paso a su expresión y representación de sí, en un gesto autopoiético de propia transfiguración. Comprendiendo que llegar a ser "viable", es la norma que califica un cuerpo para toda la vida dentro de la esfera de la inteligibilidad cultural. (Butler 2018: 19).

Si comprendemos el cuerpo como ese primer territorio político de producción de identidad, "la sexualidad vertida sobre el mismo expresa el acto domesticador, apropiador cuando insemina el territorio-cuerpo de una mujer" (Segato 2013: 35). La inseminación, que refiere Segato, puede pensarse en términos de semen o también en términos de ideas, de proposiciones o prejuicios y categorías lanzados violentamente contra el territorio de lxs cuerpxs que no responden al mandato patriarcal. De esta manera, puede comprenderse que aquel señor que sugirió a Effy que nunca iba a ser mujer por no menstruar, la inseminó del extendido determinismo cultural, civilizatorio y colonialcapitalista que no hizo más que ordenar sus funciones, sus capacidades, sus deseos. Y en este sentido, citando a Karkazis en Adiós al Futuro "el cuerpo lejos de ser un todo orgánico autoevidente, es como mucho una construcción nominal y un espacio fantasmagórico imaginado muy diferentemente a través del tiempo y a través de contextos culturales muy variados” (2018: 12). Las imágenes fantasmagóricas y auráticas que la mera presencia del cuerpo menstrual de Effy suscitan en quienes miran, desarman las categorías normalizadas de todo lo visto, conocido y moralizado. Irrumpen en el (con)texto social de manera indisciplinada e irreverente. Esta textualización del género que Effy trama en su cuerpoterritorio-político, es una forma de entrelazar las múltiples líneas sensibles, sociales y culturales, que realizan una zona precisa donde la "corporalidad y textualidad tejen un continuum en el que se cruzan y entrelazan para no desatarse jamás” (Calafell Sala 2007: 91). Su acción performática efectúa esa tensión estético-política de resistencia sensible que hace efectiva la presencia vital de un deseo incómodo y poco aceptado por los dispositivos civilizatorios, y que en su insistente operatoria normalizadora no cesa de provocar heridas profundas en las vidas de quienes portan una sensibilidad diferente.

Por eso, la "culpa" que siente Effy por el daño que le generan las heridas de los discursos Revista Interinstitucional Artes de Educar. Rio de Janeiro, V. 7, N. 1 - pág. 171-189 janeiroabril de 2021: "Pedagogias Vitais: Corpo, Desejo e Educação" DOI: 10.12957/riae.2021.51642 


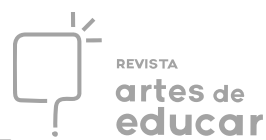

capitalistas, colonizadores, y moralistas en su cuerpx, lo necesita escribir a la vez que se inscribe la obra en el espacio: hacer cuerpx-obra-en-resistencia que necesita expresar y gritar ese dolor como forma de autoafirmación, gesto (ins)urgente de vitalidad y libertad.

\section{Devenir mujer menstrual}

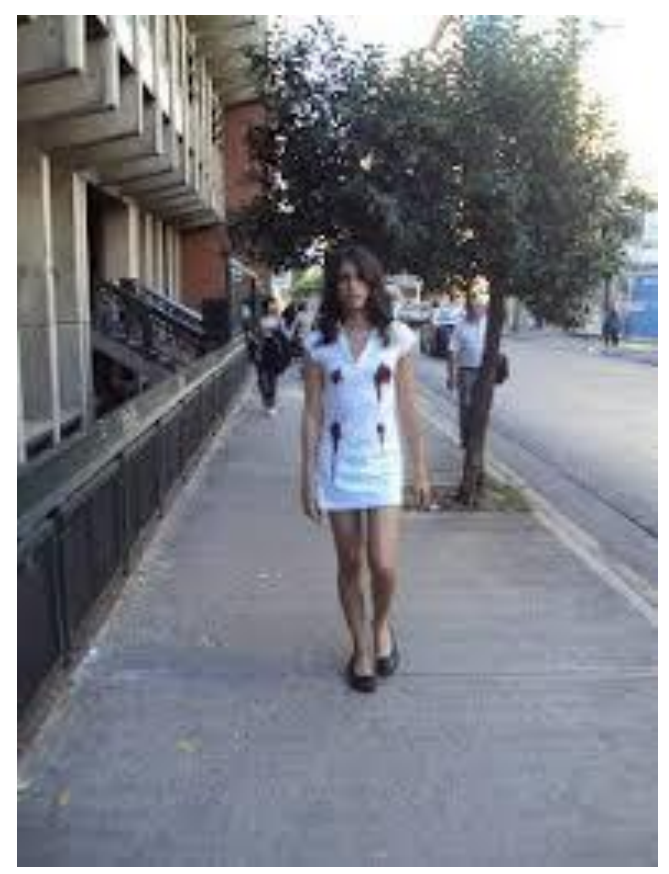

Implica habitar todas las blasfemias, insultos, vejaciones, violencias y violaciones del "ser mujer". Que un médico busque atrevidamente observar su cuerpx sin su consentimiento, o que en el espacio de lo público reciba "piropos", son algunos de los rasgos propios del habitar unx cuerpx feminizado en esta sociedad misógina.

Effy comienza a sentir el peligro de ser una mujer, comienza a hacerse las preguntas que se han formulado pragmáticamente, en un apestoso y aberrante sistema patriarcal para que nos sintamos responsables de nuestra corporalidad deseante y deseada. "Trato de contener mi llanto camino a casa no entendiendo si hice algo que justificara su atrevimiento" (Faigenbaum \& Chorubczyk 2016: 97). La artista se revisa, cuestiona su propio accionar, lo que tiene puesto, las "señales" que pudo "haber comprendido mal" el violento médico. Su cuerpx femenino es percibido, se inscribe, en esa lógica de menosprecio y subordinaciones machistas, donde ya no importa lo que hayas hecho, dicho, o incluso cómo vayas vestida, porque las violencias recalcitrantes del sistema patriarcal se ejercen sólo -y tan sólo- por no ser un cuerpo "digno" de la sexualidad masculina que rige y gobierna desde su existencia privilegiada, en esta lógica heteronormada de la civilización capitalista-colonial.

En la octava menstruación de noviembre, con todo el peso de la misoginia encima por portar un cuerpx feminizado. Effy manifiesta "Recorro las calles tal si estuviese en una pasarela de modas forzándome a experimentar vergüenza de ser mirada”. (Faigenbaum \& Chorubczyk 2016: 93). Esa vergüenza que se manifiesta, es aquella que se despliega cuando un cuerpx no sujeto al orden normalizado se exhibe de manera segura por el espacio públicopolítico. "Hablar de la mujer como materia que, pese a haber sido escrita, vuelve una y otra Revista Interinstitucional Artes de Educar. Rio de Janeiro, V. 7, N. 1 - pág. 171-189 janeiroabril de 2021: "Pedagogias Vitais: Corpo, Desejo e Educação" DOI: 10.12957/riae.2021.51642 
vez sobre sí misma para rescribirse, supone aceptar también la importancia de la mirada, -la suya y la del otro- como elemento articulador" (Calafell Sala 2007: 91). La mirada entendida como dispositivo colonizado(r), educado(r) y orientado(r), domestica el accionar válido en los marcos socialmente viables, aceptables e inteligibles. "Porque la normalidad es un cuerpo de cuya existencia indecible nada decimos y la normalidad es la existencia de un cuerpo decible y dicho y vuelto a decir" (Skliar 2014: 191). Pero que, en esa iteración de decires, en ese repliegue permanente de la palabra, el silencio efectivo de lo diferente, sufre un desgarro en sus entrañas, mucho más doloroso que cualquier discriminación proferida, porque el silenciamiento se vuelve una pesada atmósfera que acompaña hasta en los sueños, pesadillas heredadas de una noche tormentosa, una larga noche llamada patriarcado.

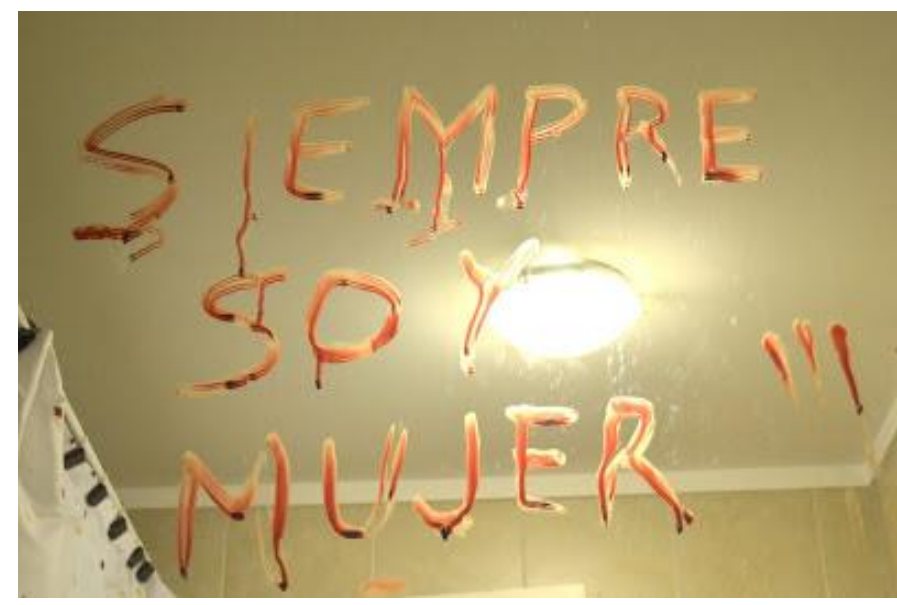

Es necesario conjurar esa oscuridad heredada, conjurar y ritualizar el desprendimiento de todas esas ligaduras indeseadas, por eso Effy necesita delimitar un círculo con sangre menstrual, ese grito corporante de sangre menstrual y voz encarnada que la nombra, sangre menstrual refugio de la incomprensión ajena, que repara las vejaciones iteradas y escritas sobre su cuerpx femenino.

"Utilizo mi menstruación para escribir una frase en un espejo donde puedo ver mi cuerpo completo" (Faigenbaum \& Chorubczyk 2016: 106). Percibirse en cuerpx completo es integrar las fragmentaciones históricas de un desmembramiento. Dolorosas parcelaciones de funciones y capacidades extirpadas, recluidas y arrebatadas, y a su vez, es enfrentar en plena desnudez un vacío inminente, un hueco oscuro en la imagen de sí, que hace de esa presencia que la pedagogía masculinizante se ha encargado de clausurar por ser el resto, el residuo del hombre (Calafell Sala 2007: 93). "Ese espejo representa mi encuentro cotidiano conmigo misma, forzándome a convivir con mi realidad y no huir de ella" (Faigenbaum \& Chorubczyk 2016: 113). El gesto performático de Effy porta una valentía muy particular, la arriesgada presencia de enfrentarse a lo que es, con todas sus heridas y vejaciones a piel ardiente, irritada de las fricciones heteronormalizadoras, y supurando el hedor jadeante de una sociedad instigadora y atormentadora.

Se hace necesario hurgar en lo profundo de la propia carne envenenada, contaminada de esa maldición social, y para ello, la escritura es la herramienta (en su composición Revista Interinstitucional Artes de Educar. Rio de Janeiro, V. 7, N. 1 - pág. 171-189 janeiroabril de 2021: "Pedagogias Vitais: Corpo, Desejo e Educação" DOI: 10.12957/riae.2021.51642 


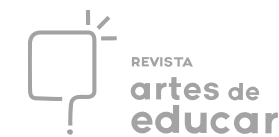

performática) que más potencia el sentido de una transfiguración conjurante de todo ese embrujo. Escribirse en el cuerpo los signos de un deseo de vida, que expande el mundo posible de ser imaginado como un espacio habitable, es el acto mismo que realiza Effy al subrayar su nombre, y no tacharlo como la sociedad misógina y patriarcal ha realizado sobre su existencia durante tanto tiempo. "Con mis genitales masculinos bañados en la sangre que representa mi menstruación no tacho sino subrayo la palabra Mujer" (Faigenbaum \& Chorubczyk 2016: 107).

Escribirse desde el cuerpo su propia imagen vital de deseo, es desocultar la matriz sensible que da sentido a su vida, recuperarla en la escritura, conjurarla, y hacerla emerger en medio de tanta ignominia como un cuerpx, una vida que merece ser vivida. La performance es un modo estético-político de conjurar las dominaciones, las opresiones y violencias ultrajantes de un sistema que no descansa ni da tregua, su potencia es la resistencia corporante que más allá de desobedecer, también afirma una existencia singular. "Mi intención es mostrar, sentir y ser sin representar, presentándose. $Y$ aunque vulnerabilidad tenemos todos, esta forma de hacer me permite apropiarme de mi cuerpo. Para mí, la performance es un lugar de poder y autoconocimiento que me salva de quedarme atrapada y sola sintiendo cosas sin que se entere nadie en el mundo." (Treibel \& Beth 2013).

Si los relatos son construidos a partir de la red de relaciones entre lo imaginario, lo fantaseado, y el mundo que podría llegar a denominarse como "real", y si "lo característico de la literatura es su verosimilitud, lo que sin ser real, es creíble y convincente" (Laguna González, 2005: 6), es posible pensar la experiencia autobiográfica de Effy como una intervención de autocreación, donde la verosimilitud no sólo (re)crea una ficción de sí misma para la que convoca en cada caso (en cada performance) a su público, sino que además disputa los sentidos de lo real, lo creíble y lo ilusorio. ¿Qué es ficción o artificio, cuando al meter la mano en los genitales muestra sangre y afirma que menstrúa y es mujer? ¿Es real lo que otrxs puedan decir sobre su ser, sobre su devenir? o ¿es real la construcción del relato que la artista (co)crea y construye para sí? En esa zona indiscernible para las categorías lógico-epistémicas, incluso hasta metafísica, de la tradición moderno-colonial que gobiernan la construcción social y política de la realidad, es donde Effy hace una fiesta, un carnaval de sentido, una punzante y risueña mueca que desestabiliza todos los órdenes heredados, para abrir un sentido nuevo, para gestar una vida (im)posible. 
Nunca serás mujer, desterritorializa lxs cuerpxs menstruantes, y también, lxs cuerpxs

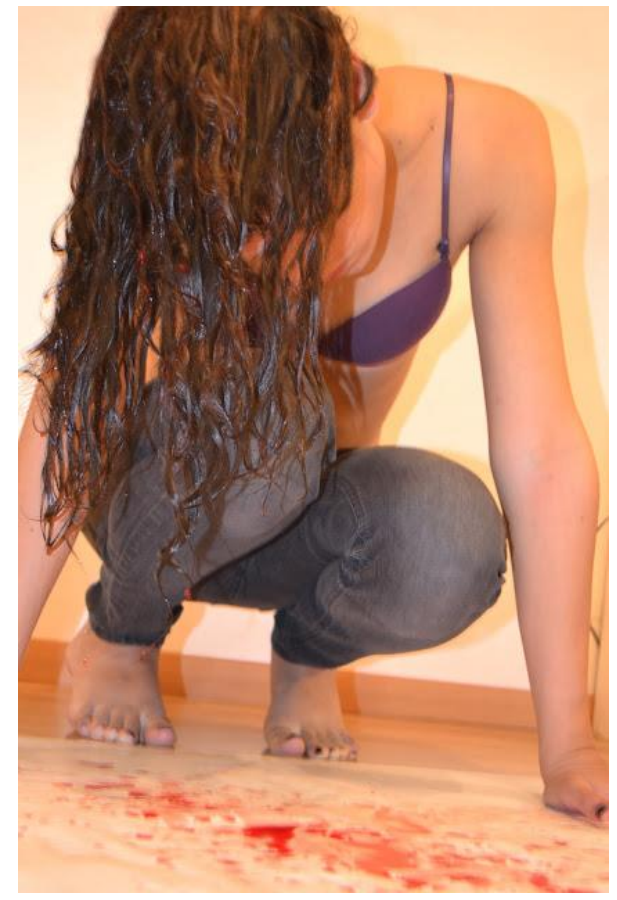
gestantes. Ante la inminencia de otro arrebato funcional, el de la gestación, Effy hace de su mente y sus ideas una matriz fértil de producción, donde la gestación de imágenes, performances y obras, es el modo de componer su deseo creador, su forma de vida otra, portando el profundo sentido de abrir camino a todxs lxs que vendrán: "Mi mente es mi aparato reproductor femenino: fértil y capaz de reproducir ideas para que formen parte de la siguiente generación." (Faigenbaum \& Chorubczyk 2016: 104). Su fertilidad de ideas, como bien dice, desterritorializa la función de gestación femenina, transfigura su capacidad para desestabilizar el orden capacitista que la modernidad colonial ha instaurado los cuerpos femeninos, donde se manda a la mujer a procrear hijxs, y a su vez se le extirpa toda posibilidad de pensamiento.

Effy realiza una contraofensiva sensible al ordenamiento histórico del heteropatriarcado, haciendo de su imposibilidad heredada una potencia viva de afirmación creadora: "el útero es mi cerebro" (Treibel \& Beth 2013).

Esta artista conmovedora, incansablemente aguerrida y excepcional en sus modos e ideas, no sólo utilizó la materialidad de su cuerpx para ficcionalizar una historia del género, las construcciones sociales binarias del heteropatriarcado, y los signos encarnados de todos sus dispositivos de dominación, sino que atendió a todas las narrativas interseccionales incorporando, por ejemplo, la dimensión espacio-temporal y política del discurso. De (re)presentarse y "dar el presente" con sangre en la mano, al traer la memoria viva de una historia de ocultamientos, silenciamientos y desapariciones que nuestra historia nacional ha reivindicado como el modo dilecto de los gobiernos intolerantes y fascistas. Dar el presente de las ausencias políticas, forzadas, y mucho más las ausencias diarias que no son reconocidas ni valoradas, en su presencia legítima y diferencial, es el modo en que la vida de Effy se vuelve una presencia estético-política que interroga, desafía e incomoda, pero que también colabora con entrecruzar los relatos silenciados, poco escuchados, las historias que se tejen por lo bajo y en secreto, de esos cuerpxs, de esas vidas que se entraman en las comunidades minoritarias, disidentes y antinormativas. 


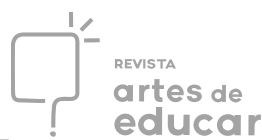

La voz de Effy es un grito-cuerpx que la excede y resuena en las entrañas latentes de todas aquellas vidas que han sido, de una u otra manera, violentadas, ultrajadas y menospreciadas por este sistema heteropatriarcal capitalista y colonial, que rige desde hace tanto tiempo e impone las condiciones de existencia para todo aquello que pretende nombrarse y vivir armónicamente con/en su territorio. Por eso, la presencia de Effy y su cuerpx-menstrual, gestante de ideas activas, amante creadora de las mutaciones alegres. Es una existencia irreverente que obliga a reivindicar la rebeldía de una ética del deseo, ante la racionalidad de la conciencia civilizada y moralmente normalizada, como un gesto vital de profunda resistencia sensible, donde lo que se desea profundamente, es ver arder el sistema opresor y colonial, extractivista, capitalista y patriarcal, que sucumba, que vomite descarnadamente su veneno, y ante semejante espectáculo que el mundo entero tiemble...

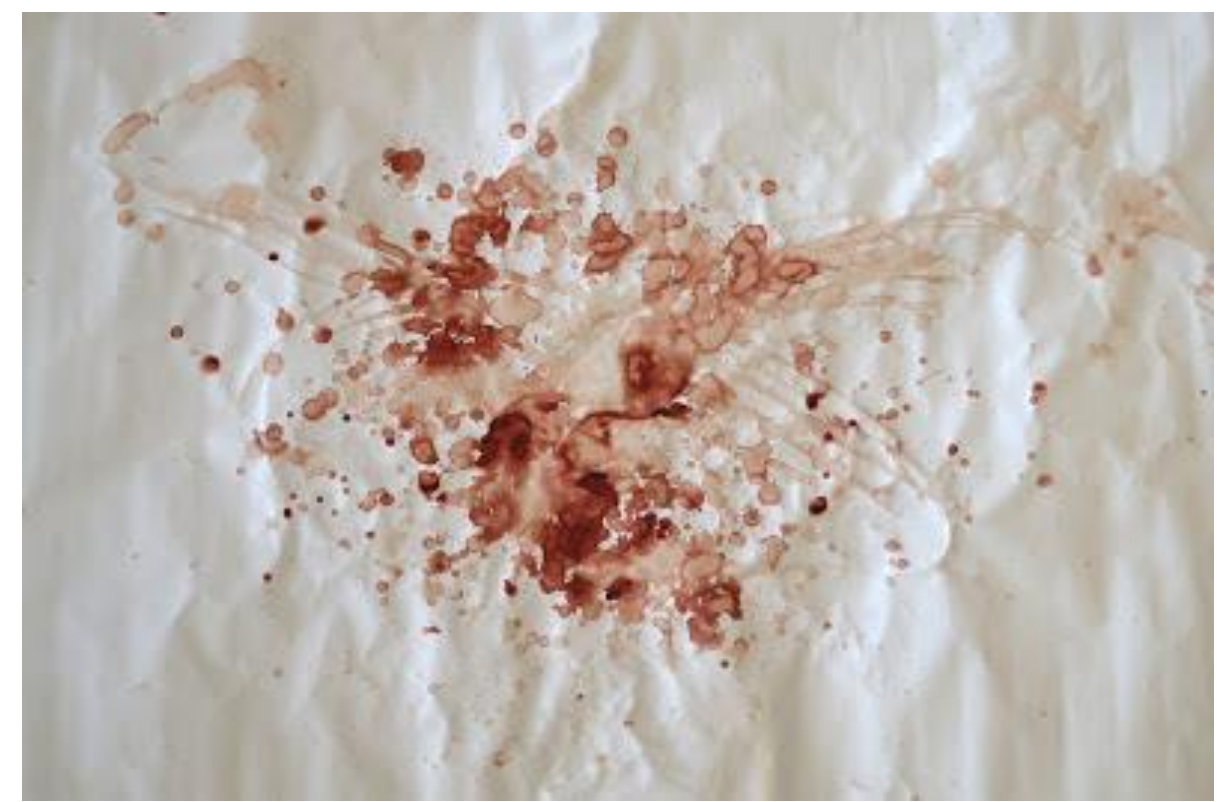

\section{REFERENCIAS:}

AHMED, S. (2019) Fenomenología Queer: orientaciones, objetos, otros. Barcelona: Bellaterra.

AlCÁZAR, J. (2014) Performance. Un arte del yo. Autobiografía, cuerpo e identidad. México: Siglo XXI.

BIGLIA, B. \& LLORET, I. (2010) Generando géneros y patologizando sujetos, en Missé, M. \& Coll-Planas, G. El Género Desordenado. Críticas en torno a la patologización de la transexualidad. Barcelona. Editorial Egales. 
BUTLER, J. (2010) Prólogo Transexualidad, transformaciones traducido por Preciado, B. en Missé, M. \& Coll-Planas, G. El Género Desordenado. Críticas en torno a la patologización de la transexualidad. Barcelona. Editorial Egales.

BUTLER, J. (2018) Cuerpos que importan. Bs As.: Paidós.

CALLAFELL SALA, N. (2007) Textualidades femeninas: la auto(bio)grafía en Victoria Ocampo, Norah Lange y Alejandra Pizarnik en Extravío. Revista electrónica de literatura comparada, Número 2. Univ. autónoma de Barcelona.

DE LAURETIS, T. (2014) Cuándo las lesbianas no éramos mujeres. traducido por Gaby Herczeg. Bocavulvaria.

DIDI HUBERMAN, G. (2017) Lo que vemos, lo que nos mira. Bs As.: Manantial.

DELEUZE, G. \& GUATTARI, F. (2010) El antiedipo: capitalismo y esquizofrenia. Bs. As.: Paidos.

FAIGENBAUM, D \& CHORUBCZYK, M. (2016) Que el mundo tiemble: cuerpo y performance en la obra de Effy Beth. La Plata: EDULP.

FOUCAULT, M. (2008) Tecnologías del yo y otros textos afines. Bs. As.: Paidós.

KARKAZIS, K. (2018) Fixing sex, en Adiós al Futuro El libro INTERSEXUAL. Ciudad de México: Diecisiete.

LAGUNA GONZÁLEZ, M. (2005) Escritura autobiográfica, en LINDARAJA. Revista de estudios interdisciplinares. Número 3. Foro universitario de Realidad y ficción.

MARTÍNEZ LUNA, S. (2019) Cultura visual. La pregunta por la imagen. Bs As. Sans Soleil.

MUÑOZ, J. (2020) Utopía queer. El entonces y allí de la futurabilidad antinormativa. CABA: Caja negra.

PRECIADO, B. (2000) Manifiesto contra-sexual. Madrid: Opera Prima.

POLLOCK, G. (2013) Visión y diferencia. Feminismo, feminidad e historias del arte. Bs As.: Fiordo.

REGUillo CRUZ, R. (2014) Políticas de la mirada, en Dussel, I. \& Gutiérrez (comps.) Educar la mirada. Políticas y pedagogías de la imagen. Bs As.: Manantial, Flacso, Osde

ROLNIK, S. \& BARDET, M. (2018) Excursus: ¿Cómo hacernos un cuerpo?, en Gago, V.; Gutiérrez Aguilar, R.; Draper, S.; Menéndez Díaz, M.; Montanelli, M.; Rolnik, S.; Bardet, M.: 8M Constelación feminista. ¿Cuál es tu lucha? ¿Cuál es tu huelga? CABA: Tinta Limón, pp. 109-131.

SEGATO, R. (2013) La escritura en el cuerpo. Bs. As.: Tinta Limón. 
SKLIAR, C. (2014) Palabras de la normalidad, en Dussel, I. \& Gutiérrez (comps.) Educar la mirada. Políticas y pedagogías de la imagen. Bs. As.: Manantial, Flacso, Osde.

TREIBEL, G. \& BETH, E. (2013) El cerebro es mi útero, entrevista a Effy Beth, publicada en Página 12, viernes 2 de agosto de 2013 en el suplemento Las12. (Revisado el 10/06/2020). Disponible en: https://www.pagina12.com.ar/diario/suplementos/las12/13-8212-2013-08-02.html

WITTIG, M. (2018) El pensamiento heterocentrado y otros ensayos. Santa Fé. Bocavulvaria. http://nuncaserasmujer.blogspot.com/p/el-proyecto.html

\footnotetext{
${ }^{\text {i }}$ Profesora y Diseñadora en Comunicación Visual (UNLP). Se formó en Educación, Imágenes y Medios (FLACSO). Realizó la Diplomatura en Construcción de Proyecto en Ciencias Sociales IDES- FpyCS UNLP. Doctoranda en Educación por la UNR. Actualmente trabaja como docente en la Facultad de Humanidades (UNMdP) y en una escuela secundaria técnica. Forma parte del Grupo de Investigación del GIIEC - CIMED. Y del Grupo de Extensión PedagOrgía dependiente de la FH de la UNMdP. Coordinadora del Observatorio de Género y Diseño en el Laboratorio de Investigación en Comunicación Visual de la Facultad de Artes de la Universidad Nacional de La Plata. Necochea, Argentina. E-mail: obaronezallocco@gmail.com ORCID: 00000003-0628-3016

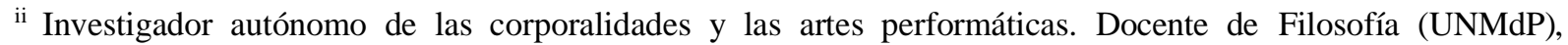
Especialista en Epistemologías del Sur (Clacso), Diplomado en Educación Sexual Integral (UNSAM). Le debe a la Maestría en Estéticas Contemporáneas Latinoamericanas (UNDAV) la investigación sobre las corporalidades estético-políticas de las prácticas performáticas decoloniales latinoamericanas. Realiza actualmente una tesis en el Doctorado en Educación de la Universidad Nacional de Rosario, sobre las epistemologías y las pedagogías decoloniales que las performances corporantes favorecen en nuestras territorialidades del sur. Es docente de Antropología de los Cuerpos en el ISFD84 y en el Instituto del Profesorado de Arte en la Carrera de DanzaExpresión Corporal. Autor de "Juegos de la Subjetividad. Imágenes lúdicas en Gilles Deleuze", publicado en 2012. E-mail: ludosofias@gmail.com ORCID: 0000-0002-7804-2070
} 